\title{
Design and analysis of cold stamping process for the car beam left/right section
}

\author{
Yang XU ${ }^{1, a}$, Penghao $\operatorname{LIAN}^{1, b}$, Haipeng $\mathrm{LI}^{1, \mathrm{c},{ }^{*} \text {, Lihui Wang }}{ }^{2, \mathrm{~d}}$ \\ ${ }^{1}$ School of Materials Science and Engineering, Hebei University of Technology, Tianjin 300130, \\ China \\ ${ }^{2}$ Automobile Engineering Department, Academy of Military Transportation, Tianjin 300161, China \\ a550489451@qq.com, ${ }^{\mathrm{b}} 646081368 @ q q . c o m,{ }^{\circ} \mathrm{lhpcx@163.com} \mathrm{("Corresponding} \mathrm{author),}$ \\ dihuiwang1976@sina.com
}

\begin{abstract}
Keywords: Car beam left/right section, Cold stamping, Forming process, Simulation analysis, Process parameters

Abstract. The cold stamping forming processes of the car beam left/right section were designed and analyzed using the CAD/CAE technology and related software. Based on the establishment of the numerical model for the car beam left/right section, the stamping processes of the product were determined through the technical analysis. In particular, the effects of different drawing schemes and parameters (including blank-holder force, blank size, lubrication conditions, etc) on the manufacturability of the product were investigated by numerical simulation technology. The forming effects were evaluated according to forming limit diagram and thickness distribution diagram. As a result, the reasonable process design and optimum parameters are obtained, which can reduce the tendencies of wrinkling, cracking and thickness reduction, and achieve sufficient plastic deformation of the blank.
\end{abstract}

\section{Introduction}

In recent years, product life cycles have been reduced by a half, which puts greater pressure on manufacturing, leading time reduction while maintaining quality and cost [1]. The longer die design cycles restrict the vehicle renewal speed in a large extent and are difficult to meet the demands of the rapid development of the automotive industry $[2,3]$. Hence, it has great significance for automakers to apply advanced die design technology during designing the forming process of automobile parts to reduce design cycle and cost.

The formability of stamping products is generally determined by the factors including die structure, sheet metal performance, blank size, blank-holder force, lubrication conditions and so on. Nonetheless, in the traditional die design method, the forming process analysis of complex stamping products, which cannot take advantage of the empirical formula, mainly depended on the experience of designers and experts. Furthermore, the die may require being tested and repaired repeatedly, which greatly increases the design cycles and is difficult to guarantee the manufacturing precision. $\mathrm{CAD} / \mathrm{CAE} / \mathrm{CAM}$ technology is a powerful tool to reform the potential defects during die designing and manufacturing. The numerical simulation based on the theoretical analysis is paid more and more attention on account of providing strong technical supports for the modern die design and manufacturing $[4,5]$.

Herein, the cold stamping forming processes of the car beam left/right section were designed and analyzed using the CAD/CAE technology and related software. The effects of different drawing schemes and parameters (including blank-holder force, blank size, lubrication conditions, etc) on the manufacturability of the product were investigated. Besides, the orthogonal experiments were applied to find out the optimum forming process parameters. The forming effects were evaluated according to forming limit diagram and thickness distribution diagram. According to the analysis results, the influence extent of each factor was shown and the feasible process solution was determined. 


\section{Numerical model of the product}

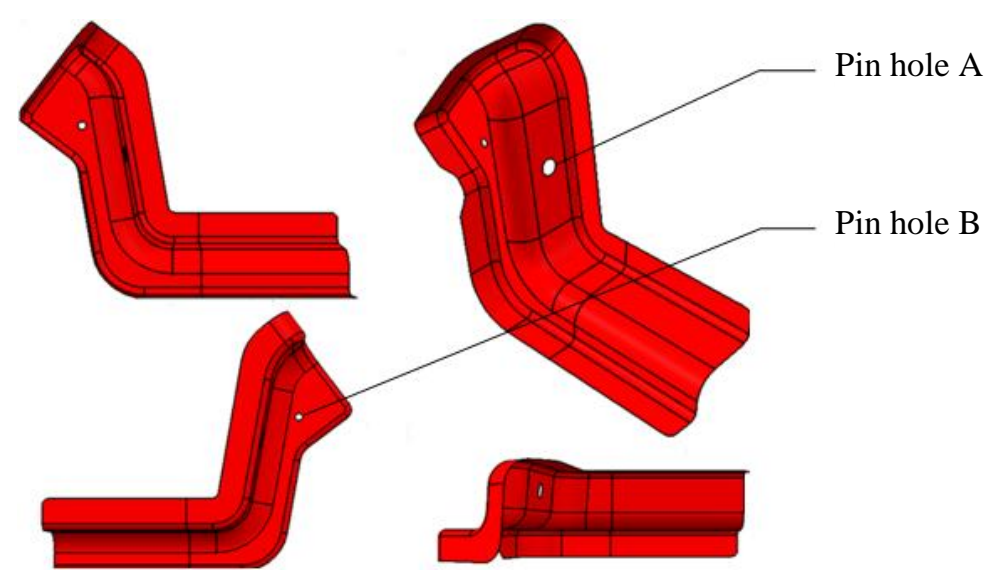

Fig.1 Numerical model of the car beam left/right section

The material of the car beam left/right section is cold-rolled steel plate DC03 with the thickness of $2.0 \mathrm{~mm}$, which has excellent mechanical and drawing performances. According to the sketch of the car beam left/right section, the numerical model of the product was established, as shown in Fig. 1.

\section{Process analysis and determination of stamping procedures}

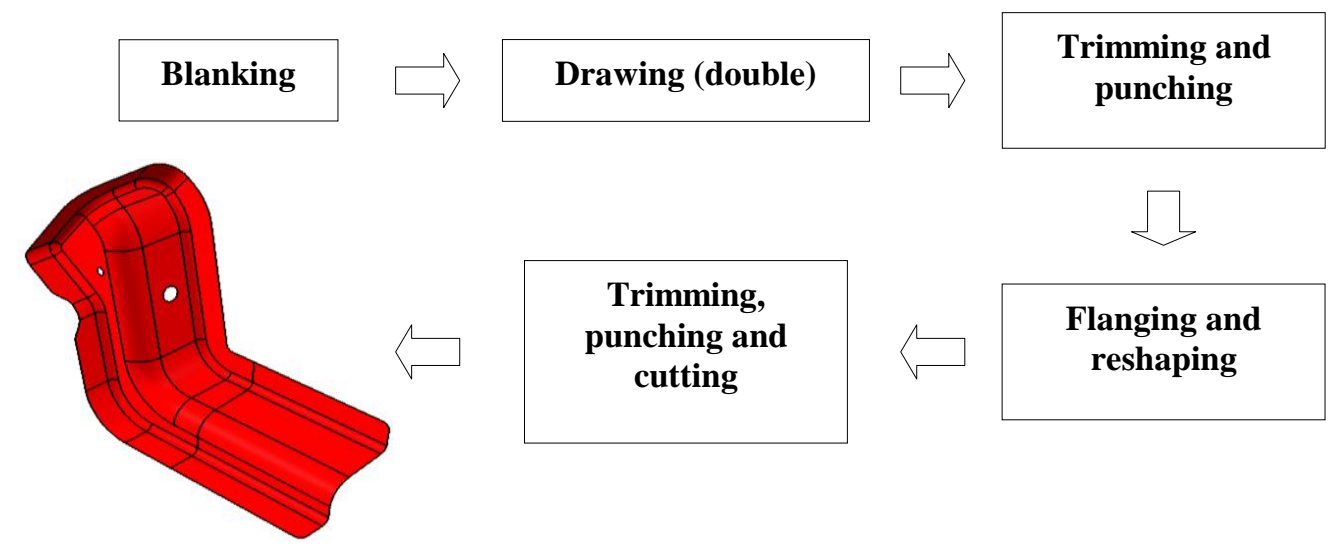

Fig. 2 Stamping procedures

As shown in Fig. 1, the product is a stretch bending part. There are two pin holes on the two sides for assembling and positioning. In order to play the roles of fixing and strengthening, it is necessary for the product to achieve the quality demands, such as a smooth surface, no excessive thickness reduction, no local wrinkling and cracking. In the practical application, the car beam left/right section is symmetric and can be used in pairs. Thus, to ensure the symmetry of the two parts' shape and size, double stamping method should be used, that is, the left section and right section are formed simultaneously in one drawing procedure following by cutting. The product can be produced precisely and efficiently with this method. At the same time, punching procedure should be after drawing to ensure the precision of the two pin holes. Based on the technical analysis, the forming solution of the product could be chosen as following: blanking, drawing (double), trimming and punching, flanging and reshaping, trimming, punching and cutting, as shown in Fig. 2. 


\section{Determination of drawing process and related parameters}

Whether to use blank-holder? Whether to set the blank-holder actually refers to whether to apply the blank-holder force or not. To determine this, the method of controlling variable was adopted, that is, only the variable of blank-holder force was changed, while other process parameters were kept consistent. With the drawing speed $(V)$ of $5000 \mathrm{~mm} / \mathrm{s}$ and die gap $(Z)$ of $2.2 \mathrm{~mm}$, two groups of blank-holder forces $(F)$ were designed. Group one: without $F$; Group two: with $F$ of $400 \mathrm{kN}$. The corresponding forming limit diagram (FLD) is shown in Fig. 3.

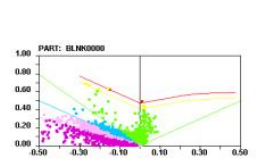

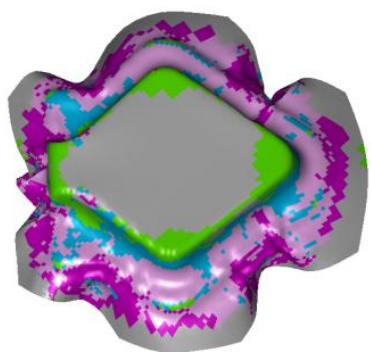

(a) Without $F$
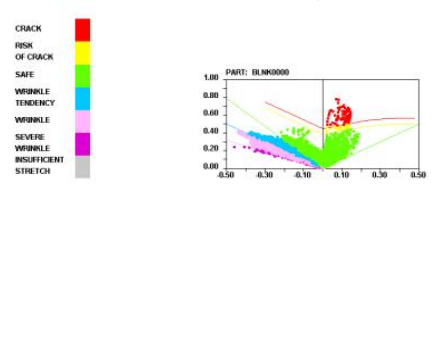

(b) With $F$ of $400 \mathrm{kN}$

Fig. 3 FLD with or without blank-holder force

It can be found that, if there is no blank-holder force, there are serious wrinkling (purple areas in Fig. 3a) at the corner and insufficient elastic deformation (gray areas in Fig. 3a) at the bottom of the drawing part, indicating the poor deforming effect. In case of applying blank-holder force, as shown in Fig. 2b, the forming effects are improved obviously. Plastic deformation appears in most areas of the product and wrinkling is reduced dramatically. But the bottom corner of the part still has a little crack, which is because the blank-holder force or drawing speed is too large [6,7], and can be eliminated by optimizing the drawing process parameters. The results indicate that the blank-holder is indispensable for the formation of the product.

Selection of lubrication condition. In the drawing process, good lubrication plays important roles in reducing friction and avoiding drawing defects. Therefore, three kinds of lubrication conditions were designed according to theory calculation and experience. The first group is no lubrication and friction coefficient $(\mu)$ is 0.17 . The second group is solid lubrication and $\mu$ is 0.125 . The third group is liquid lubrication and $\mu$ is 0.05 . With the drawing parameters of $V=5000 \mathrm{~mm} / \mathrm{s}, Z=2.2 \mathrm{~mm}$ and $F=400 \mathrm{kN}$, the FLD of three groups of lubrication conditions are shown in Fig. 4. 


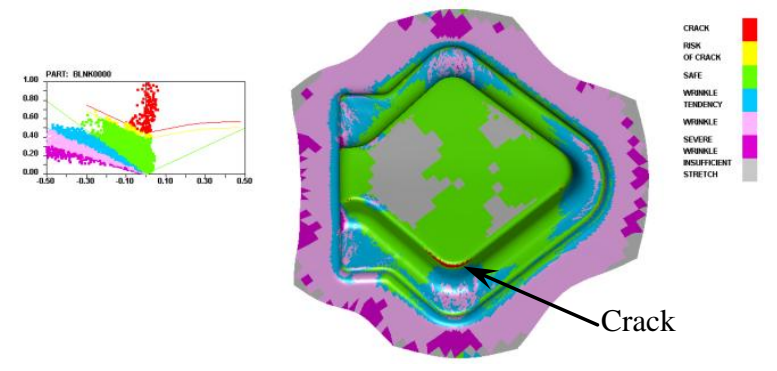

(a) $\mu=0.17$
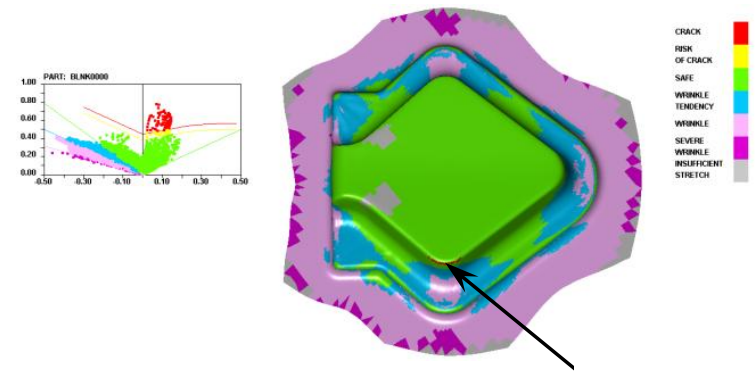

(b) $\mu=0.125$
Crack

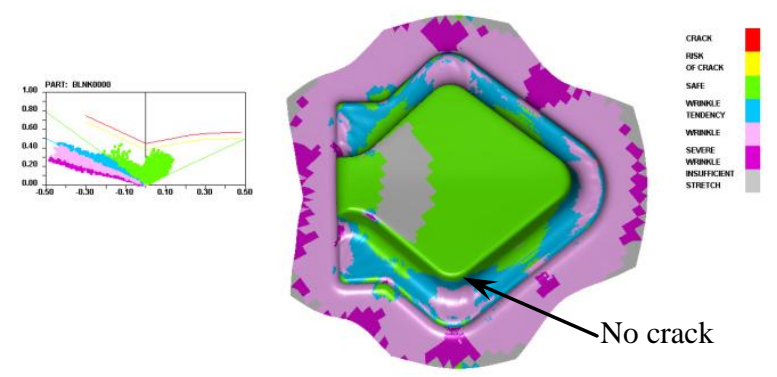

(c) $\mu=0.05$

Fig. 4 FLD of three groups of lubrication conditions

As can be seen from Fig. 4, the smaller the friction coefficient is, the smaller the cracking tendency becomes, especially at the bottom corner of the part. It is because the flow resistance of the material is lowered when the friction coefficient is smaller, which can improve terminal stretching coefficient of material so as to produce positive effect on the formability. Consequently, $\mu=0.05$, that is, oil lubrication is a good choice.

Determination of the blank size. In the drawing process, the blank size has important effects on the forming quality. If the blank size is unsuitable, drawing defects such as wrinkling, cracking and serious thickness reduction may appear. So suitable blank size is needed to improve the forming effect [8]. According to the blank size estimated in advance, the blank was designed as square tentatively and three groups of blank size were tried, $410 \times 410 \mathrm{~mm}, 430 \times 430 \mathrm{~mm}$ and $450 \times 450 \mathrm{~mm}$. With the drawing parameters of $V=5000 \mathrm{~mm} / \mathrm{s}, Z=2.2 \mathrm{~mm}$ and $F=400 \mathrm{kN}$, the numerical simulation results are shown in Fig. 5.

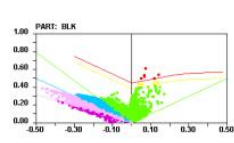

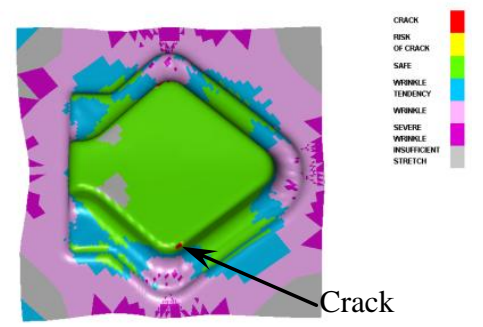

(a) $410 \times 410 \mathrm{~mm}$
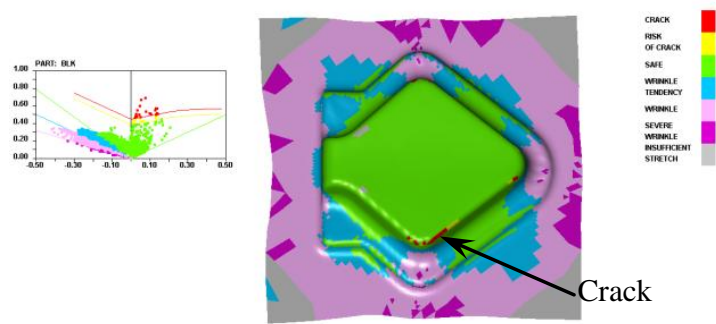

(b) $430 \times 430 \mathrm{~mm}$

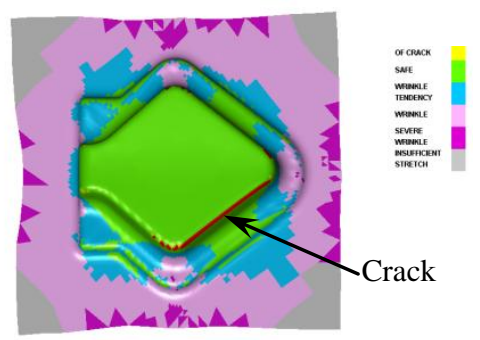

(c) $450 \times 450 \mathrm{~mm}$

Fig. 5 FLD of three groups of blanks with different geometrical sizes 
From Fig. 5, it can be seen that serious wrinkling appears at the edge of the drawing part, and the cracking phenomenon becomes more severe with the rise of blank size. Considering the material utilization and the forming effect, the blank size of $430 \times 430 \mathrm{~mm}$ is chosen and its drawing defects will be eliminate further by the optimization of other process parameters.

Orthogonal experiment of process parameters. According to the study on the blank-holder force, lubrication condition and blank size, it can be found that the drawing semi-finished part can be formed and the overall forming effect is acceptable except the crack at the bottom corner and the wrinkle at the flange corner, which can be improved by optimizing the combination of different process parameters. Considering the interactive influences of different process parameters, the orthogonal experiment analysis of some process parameters was performed. The levels of orthogonal experiment factors were shown in Tab. 1 and the orthogonal experiment groups were shown in Tab. 2 $[9,10]$. The sorted orthogonal experiment simulation results were shown in Tab. 3 .

Tab. 1 Levels of orthogonal experiment factors

\begin{tabular}{cccc}
\hline No. & $\begin{array}{c}\text { Die gap } \\
(\mathrm{mm})\end{array}$ & $\begin{array}{c}\text { Drawing speed } \\
(\mathrm{mm} / \mathrm{s})\end{array}$ & $\begin{array}{c}\text { Blank-holder force } \\
(\mathrm{kN})\end{array}$ \\
\hline 1 & 2.1 & 1000 & 200 \\
2 & 2.2 & 5000 & 400 \\
3 & 2.3 & 9000 & 600 \\
\hline
\end{tabular}

Tab. 2 Orthogonal experiment groups

\begin{tabular}{cccc}
\hline No. & $\begin{array}{c}\text { Die gap } \\
(\mathrm{mm})\end{array}$ & $\begin{array}{c}\text { Drawing speed } \\
(\mathrm{mm} / \mathrm{s})\end{array}$ & $\begin{array}{c}\text { Blank-holder force } \\
(\mathrm{kN})\end{array}$ \\
\hline 1 & $2.1(\mathrm{~A} 1)$ & $1000(\mathrm{~B} 1)$ & $200(\mathrm{C} 1)$ \\
2 & $2.1(\mathrm{~A} 1)$ & $5000(\mathrm{~B} 2)$ & $400(\mathrm{C} 2)$ \\
3 & $2.1(\mathrm{~A} 1)$ & $9000(\mathrm{~B} 3)$ & $600(\mathrm{C} 3)$ \\
4 & $2.2(\mathrm{~A} 2)$ & $1000(\mathrm{~B} 1)$ & $400(\mathrm{C} 2)$ \\
5 & $2.2(\mathrm{~A} 2)$ & $5000(\mathrm{~B} 2)$ & $600(\mathrm{C} 3)$ \\
6 & $2.2(\mathrm{~A} 2)$ & $9000(\mathrm{~B} 3)$ & $200(\mathrm{C} 1)$ \\
7 & $2.3(\mathrm{~A} 3)$ & $1000(\mathrm{~B} 1)$ & $600(\mathrm{C} 3)$ \\
8 & $2.3(\mathrm{~A} 3)$ & $5000(\mathrm{~B} 2)$ & $200(\mathrm{C} 1)$ \\
9 & $2.3(\mathrm{~A} 3)$ & $9000(\mathrm{~B} 3)$ & $400(\mathrm{C} 2)$ \\
\hline
\end{tabular}


Tab. 3 Orthogonal experiment simulation results

\begin{tabular}{|c|c|c|c|c|c|c|c|}
\hline \multirow[b]{2}{*}{ No. } & \multirow[b]{2}{*}{$\begin{array}{c}\text { Die gap } \\
(\mathrm{mm})\end{array}$} & \multirow[b]{2}{*}{$\begin{array}{l}\text { Drawing } \\
\text { speed } \\
(\mathrm{mm} / \mathrm{s})\end{array}$} & \multirow{2}{*}{$\begin{array}{l}\text { Blank- } \\
\text { holder } \\
\text { force } \\
(\mathrm{kN})\end{array}$} & \multicolumn{4}{|c|}{ Evaluation index } \\
\hline & & & & $\begin{array}{l}\text { Minimum } \\
\text { thickness } \\
(\mathrm{mm})\end{array}$ & Cracking & Wrinkling & $\begin{array}{l}\text { Insufficient } \\
\text { plastic } \\
\text { deformation }\end{array}$ \\
\hline 1 & 2.1(A1) & $1000(\mathrm{~B} 1)$ & $200(\mathrm{C} 1)$ & 1.383 & small & small & small \\
\hline 2 & 2.1(A1) & $5000(\mathrm{~B} 2)$ & $400(\mathrm{C} 2)$ & 1.312 & $\begin{array}{l}\text { slightly } \\
\text { larger }\end{array}$ & smaller & small \\
\hline 3 & 2.1(A1) & 9000(B3) & $600(\mathrm{C} 3)$ & 1.328 & $\begin{array}{l}\text { slightly } \\
\text { larger }\end{array}$ & larger & $\begin{array}{l}\text { slightly } \\
\text { larger }\end{array}$ \\
\hline 4 & $2.2(\mathrm{~A} 2)$ & $1000(\mathrm{~B} 1)$ & $400(\mathrm{C} 2)$ & 1.434 & small & smaller & smaller \\
\hline 5 & $2.2(\mathrm{~A} 2)$ & $5000(\mathrm{~B} 2)$ & $600(\mathrm{C} 3)$ & 1.356 & larger & $\begin{array}{l}\text { slightly } \\
\text { larger }\end{array}$ & $\begin{array}{l}\text { slightly } \\
\text { larger }\end{array}$ \\
\hline 6 & $2.2(\mathrm{~A} 2)$ & 9000(B3) & $200(\mathrm{C} 1)$ & 1.545 & small & larger & small \\
\hline 7 & $2.3(\mathrm{~A} 3)$ & $1000(\mathrm{~B} 1)$ & $600(\mathrm{C} 3)$ & 1.477 & larger & small & smaller \\
\hline 8 & $2.3(\mathrm{~A} 3)$ & $5000(\mathrm{~B} 2)$ & $200(\mathrm{C} 1)$ & 1.492 & larger & larger & smaller \\
\hline 9 & $2.3(\mathrm{~A} 3)$ & 9000(B3) & $400(\mathrm{C} 2)$ & 1.378 & larger & larger & larger \\
\hline $\begin{array}{c}\mathrm{I}_{\mathrm{j}} \\
\mathrm{II}_{\mathrm{j}}\end{array}$ & $\begin{array}{l}4.023 \\
4.335\end{array}$ & $\begin{array}{l}4.294 \\
4.160\end{array}$ & $\begin{array}{l}4.420 \\
4.124\end{array}$ & \multirow{6}{*}{\multicolumn{4}{|c|}{$\begin{array}{l}\mathrm{I}_{\mathrm{j}}, \mathrm{II}_{\mathrm{j}}, \mathrm{III}_{\mathrm{j}} \text { : is } \mathrm{j}(\mathrm{j}=\mathrm{F}, \mathrm{n}, \mathrm{r}) \text { column } 1,2,3 \text { total minimum } \\
\text { thickness of the three levels, respectively. } \\
\overline{\mathrm{I}} \mathrm{j}, \overline{\mathrm{II}} \mathrm{j}, \overline{\mathrm{III}}_{\mathrm{j}} \text { : is } \mathrm{j}(\mathrm{j}=\mathrm{F}, \mathrm{n}, \mathrm{r}) \text { column } 1,2,3 \text { average } \\
\text { minimum thickness of the three levels, respectively. } \\
\text { Dj: range of } \mathrm{j} \text { column, } \mathrm{Dj}=\max \left\{\overline{\mathrm{I}}_{\mathrm{j}}, \overline{\mathrm{II}}_{\mathrm{j}}, \overline{\mathrm{III}}_{\mathrm{j}}\right\}-\text { min } \\
\left\{\overline{\mathrm{I}}_{\mathrm{j}}, \overline{\mathrm{II}}_{\mathrm{j}} \mathrm{\textrm {IIII } _ { \mathrm { j } }}\right\}\end{array}$}} \\
\hline $\mathrm{III}_{-}$ & 4.347 & 4.256 & 4.161 & & & & \\
\hline$\overline{\mathrm{I}}_{\mathrm{j}}$ & 1.341 & 1.431 & 1.473 & & & & \\
\hline$\underline{\overline{I I}}_{\mathrm{j}}$ & 1.445 & 1.399 & 1.375 & & & & \\
\hline $\begin{array}{l}\mathrm{III}_{\mathrm{j}} \\
\mathrm{D}\end{array}$ & 1.449 & 1.419 & $\begin{array}{l}1.387 \\
0098\end{array}$ & & & & \\
\hline $\mathrm{D}_{\mathrm{j}}$ & 0.108 & 0.032 & 0.098 & & & & \\
\hline
\end{tabular}

Through the results of orthogonal experiments analysis, it can be found that: (1) The influences of the drawing parameters on the minimum thickness are in the order of die gap>blank-holder force>drawing speed. (2) In the nine groups of numerical simulation results, the cracking is not obvious with die gap of $2.1 \mathrm{~mm}$ or $2.2 \mathrm{~mm}$. On the contrary, the groups with die gap of $2.3 \mathrm{~mm}$ have larger cracking areas. This indicates that the die gap should be in a reasonable range. Currently, the die gap is $110 \%$ of the blank thickness in practical production [11]. (3) With the blank-holder force increasing, the wrinkling at the flange corner decreases obviously. And with the drawing speed increasing, the likelihood of cracking increases. (4) Based on the evaluation principles of minimum thickness, cracking area and the likelihood of wrinkling, the optimum scheme is group 4 (A2B1C2) and the corresponding FLD and thickness distribution diagram are shown in Fig. 6. 


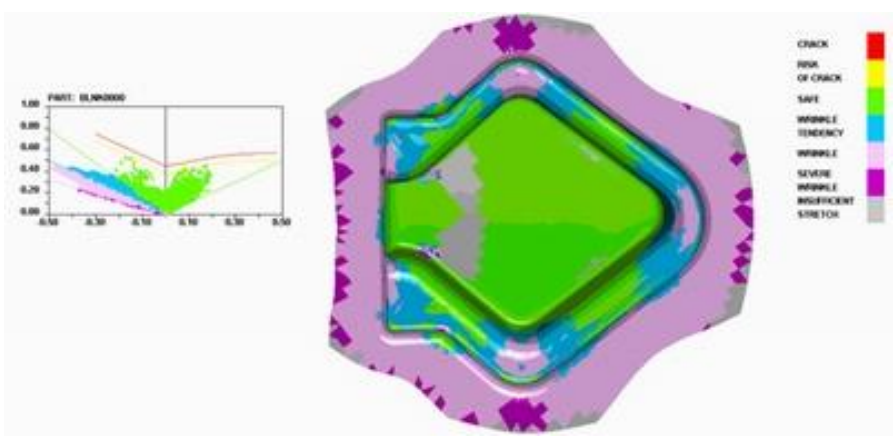

(a) Forming limit diagram

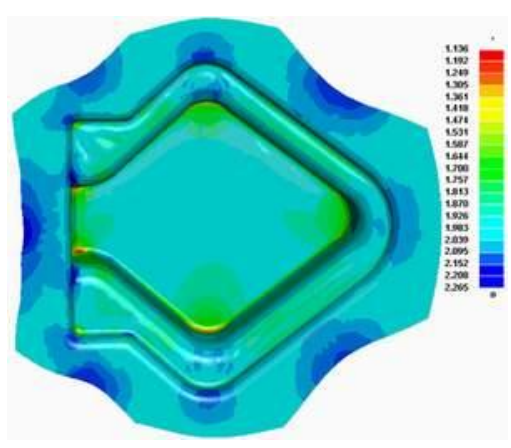

(b) Thickness distribution diagram

Fig. 6 FLD and thickness distribution diagrams of group 4

\section{Conclusion}

In this paper, the numerical simulation technology is applied to acquire the feasible forming process and the optimal process parameters for the complex automobile part. The cold stamping forming processes of the car beam left/right section were designed and analyzed using the CAD/CAE technology and related software. The forming solution involves in blanking, drawing (double), trimming and punching, flanging and reshaping, trimming, punching and cutting. The feasible forming parameters of drawing procedure include: taking oil lubrication, blank size of $430 \times 430 \mathrm{~mm}$, die gap of $2.2 \mathrm{~mm}$, drawing speed of $1000 \mathrm{~mm} / \mathrm{s}$, blank-holder force of $400 \mathrm{kN}$. By numerical simulation, the obtained forming limit diagram and thickness distribution diagram can be used to evaluate the reasonability and feasibility of process and parameter design. In a way, the design quality and accuracy of the dies can be improved and enormous time and cost can be saved as well.

\section{Acknowledgements}

The authors acknowledge the supports from Undergraduate Innovation Training Program of Hebei University of Technology and Teaching Reform Project of Hebei University of Technology.

\section{References}

[1] Nagahanumaiah, K. Subburaj and B. Ravi: Comput. Ind. Vol. 59 (2008), p. 262

[2] Y. Horikoshi, T. Kuboki, M. Murata, K. Matsui and M. Tsubokura: J. Mater. Process. Tech. Vol. 218 (2015), p. 99

[3] M. Shahbaz, R. Ebrahimi and H.S. Kim: Appl. Math. Model. Vol. 40 (2016), p. 3550

[4] S.H. Yue, G.X. Wang, F. Yin, Y.X. Wang and J.B. Yang: J. Mater. Process. Tech. Vol. 139 (2003), p. 465

[5] J. Happian-Smith: An Introduction to Modern Vehicle Design (Butterworth-Heinemann, Oxford 2002)

[6] S.J. Qin, B.Q. Xiong, H. Lu and T.T. Zhang: Trans. Nonferrous Met. Soc. China Vol. 22 (2012), p. 239

[7] R. Sekhar, A. Milad and F. Mohammad: Thin Wall. Struct. Vol. 94 (2015), p. 56

[8] K. Lin, Y.X. Zhou and L. Wang: Light Indu. Mach. Vol. 25 (2007), p. 48 (In Chinese)

[9] J. Zhu and W. Chen: Energy Vol. 77 (2014), p. 953 
[10]P.C. Guan, J.W. Fan, L.H. Wang, H.P. Li, N. Zhang and X.X. Geng: Appl. Mech. Mater. Vol. 543 (2014), p.337

[11]C.S. Chen: Cold Stamping Process and Die Design (University of Electronic Science and Technology of China Press, Chengdu 2008) (In Chinese) 